\title{
Revisiting the Operational Principle of Sustainability: Physical and Economic Aspects
}

\author{
Hidenori Nakamura ${ }^{1}$ \\ ${ }^{1}$ Institute for Global Environmental Strategies, Japan \\ Correspondence: Hidenori Nakamura, Institute for Global Environmental Strategies, Japan. E-mail: \\ hi-nakamura@iges.or.jp
}

Received: August 2, 2012 Accepted: August 23, 2012 Online Published: August 28, 2012

doi:10.5539/jsd.v5n9p98 URL: http://dx.doi.org/10.5539/jsd.v5n9p98

\begin{abstract}
This paper reviews the ideas of measuring physical and economic sustainability of human civilisation proposed by different schools of thought, namely earth sciences, ecological economics, neoclassical economics and engineering, in order to fill the cognitive gaps between the different disciplines. The paper focuses on physical material and energy flows that enable human economic activities and introduces the distinction between flow and stock, as well as that between material and energy.

It proposes a revised operational principle of sustainability, or transition towards new state of civilisation: The overall vision of a civilisation based on natural flow and man-made stock, using natural energy stock during the transition phase, supplemented by the following amended operational principle: (a) Ecological services that are needed to maintain life shall be conserved, and waste and pollution levels shall be within the natural assimilative capacity; (b) consumption shall be within the capacity of renewable resources; and (c) consumption of non-renewable resources shall be associated with investment in renewable substitutes.

The paper also provides selected indicators, following the revised operational principle: (a) Degree of dependence on natural hydrocarbon stock regarding fuel consumption for heating, transportation and other motive power as well as electricity generation; (b) Energy profit ratio (EPR) for natural hydrocarbon stock relative to natural energy stock; (c) non-energy ecological footprint for biocapacity; and (d) water stress. These could usefully indicate the past and present state and trend of sustainability, thereby suggesting future limits to human activities.
\end{abstract}

Keywords: sustainability, operational principle, indicators, earth science, economics, geo-engineering

\section{Introduction}

The sustainability of human civilisation has been framed in different ways within different disciplines. There remains considerable debate on how to best measure sustainability, even when limited to the physical and economic aspects of sustainability (Pezzey \& Toman, 2005). Neoclassical economists and experts from other disciplines have proposed different measures to assess sustainability and resource scarcity. However, the major arguments presented in environmental or economic sustainability have not fully incorporated the findings of studies within the earth sciences-perhaps because the epistemic communities of each discipline do not closely overlap and because longer-term assessments such as 100 years or more, are not well addressed. Therefore, there is a need to reframe and re-examine the ideas from different schools in order to guide and assess policies, activities, investment and research and development towards sustainable development.

In Japan, the discourse and policy of environmental sustainability is framed as the three pillars of climate change mitigation and adaptation, sound material-cycle society and biological diversity conservation (Ministry of the Environment [MOE], 2011). However, this topical description of sustainability does not provide clear ideas and measures to determine the sense in which human society is environmentally sustainable or not, nor the critical thresholds that a sustainable society would need to respect. Moreover, current frameworks do not directly address the issue of securing the resources and energy inputs to economic activities. As such, the issue of climate change mitigation is not explicitly contextualised within efforts to transition to a society where only renewable energy is produced and consumed.

Global-level assessment of environmental sustainability also tends to be topical and is not physically integrated 
in ways that can be interpreted as a holistic system. Rockstrom et al. (2009) proposed the concept of planetary boundaries defined by nine issues, including climate change, biogeochemical flow and biodiversity loss. They provided tentative thresholds for these nine boundaries, three of which were already exceeded, according to their assessment. These attempts also fail to address the issue of the physical constraints placed on human activities by resources and energy.

The physical and ecological foundations for human civilisation should be taken into account within any relevant policy process, such as sustainable development goals (SDGs). In reality, however, the principle of sustainability - especially for physical and economic aspects - is not incorporated within the discussion of governance and indicators (Kanie et al., 2012; United Nations Department of Economic and Social Affairs [UNDESA], 2012).

The Post-Gross Domestic Product (Post-GDP) proposal is also relevant to the discussion of this paper (Stiglitz et al., 2010). In addition to the discussion on quality of life, the report also analyses sustainable development and the environment. Several indicators are reviewed and the broad recommendation is made to encourage further research on appropriate physical indicators to assess the environmental aspect of sustainability. Nevertheless, the necessity of transition to a new form of civilisation is not explicitly incorporated from a physical scientific perspective, and several environmental issues are treated more or less equally.

To address this incomplete integration of the measurement of physical and economic sustainability, this paper reviews the ideas of measuring physical and economic sustainability of human civilisation presented by different schools of thought, namely earth sciences, ecological economics, neoclassical economics and engineering, in order to propose a revised operational principle of sustainability or transition towards a new state of civilisation. It also discusses useful indicators following the revised operational principle.

The paper also aims to provide additional perspectives on the discussion of peak oil (e.g., Hall, Powers, \& Schoenberg, 2008), the food-energy-water nexus (e.g., Hoff, 2011), as well as international efforts to address sustainability issues such as resource productivity and sustainable consumption and production (e.g., United Nations Environment Programme [UNEP], 2009; UNEP, 2012). In particular, this paper has direct relevance to the discussion of peak oil. It also enables a wider assessment than that of efficiency improvement.

The paper maintains the view that humans and our extended built environment as well as semi-artificial ecosystems are part of the Earth system and that physical sustainability should be assessed by material and energy flows that drive and comprise the system. The paper also examines the extent to which market mechanisms might reflect sustainability under the physical constraint.

The paper argues that the perspectives of earth sciences and ecological economics can be combined to provide broad operational principles for the sustainability transition, while the measures proposed by earth sciences, ecological economics, neoclassical economics and engineering could provide useful indicators of past and present states and the trend of sustainability, which suggest the future limits of human activities. Conventional economics would argue that the market would autonomously determine the rate of transition from fossil-fuel dependent economy to renewable energy dependent economy. However, the rate of transition to sustainable civilisation that may exceed the speed realised through the market could also be determined though collective decision making in human society. These principles and indicators provide a good basis for monitoring and evaluation of transition. Adaptive management is required, based on these principles and indicators.

This paper is structured as follows. The paper first reviews the different schools of thought regarding the physical and economic aspects of sustainability for human civilisation. The paper then proposes and discusses a revised operational principle for sustainability from physical and economic perspectives, followed by some relevant indicators. The paper also discusses the reasons that the proposed principle has not been widely adopted to date. The paper concludes with a summary and an overview of the remaining issues.

\section{Review of Different Schools of Thoughts}

\subsection{Earth Sciences}

The earth science literature that captures the formulation and maintenance of human civilisation derives from the study of the evolution of the Earth. The Earth system has evolved through a process of differentiation, driven by the cooling of the planet as well as by a process of dissipation of solar thermal radiation. The Earth system now comprises sub-systems of geosphere, atmosphere, ocean, biosphere, and anthroposphere, where the anthroposphere is defined as the sphere built and maintained by human civilisation, which has differentiated from the biosphere on the Earth's surface (Matsui, 1998a). The anthroposphere was initiated around 10,000 years ago at the end of the last ice age with the development of arable and livestock forms of human agriculture in 
addition to hunting and gathering. The anthroposphere, or human civilisation, has expanded greatly since the Industrial Revolution around 250 years ago due to the adoption of fossil fuels, or hydrocarbons, to derive energy from the chemical potential energy accumulated in underground materials.

Each sub-system of the Earth can be described as a box, where materials such as carbon and water are reserved ("stock"), and which flow in/out of the other sub-systems ("flow") (Matsui, 1998a). Figure 1 shows a schematic model of material stock and flow. The anthroposphere is utilizing material and energy flows within the Earth system to maintain its activities. Preindustrial agricultural society is a flow-dependent civilisation, whereas industrial society is a stock-dependent civilisation, which has enabled rapid expansion and accelerated human activities, in not only manufacturing and commerce but also agriculture itself. A flow-dependent civilisation is stable and has a longer lifespan, since its material and energy use is embedded within the biosphere. Conversely, a stock-dependent civilisation has a shorter lifespan, since it relies on a finite amount of accumulated stock generated in the past to drive its material and energy flows.

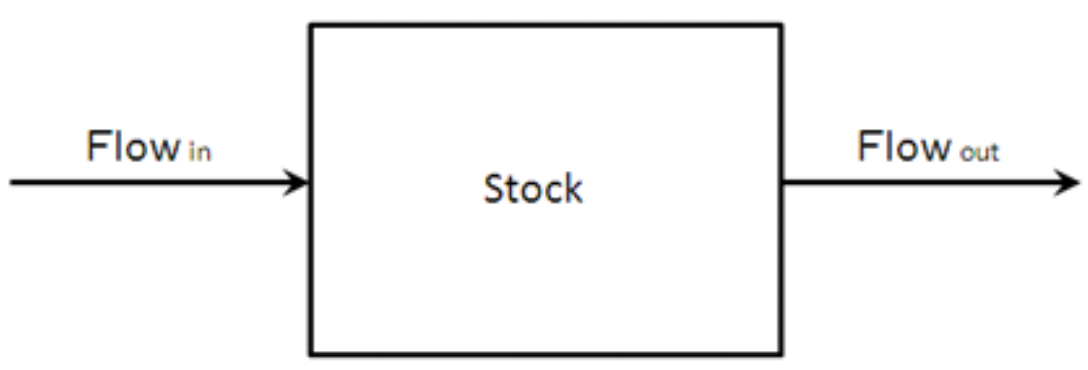

Figure 1. The box model demonstrating the concepts of stock and flow

The literature suggests the concept of the natural flow (renewable resources) and man-made stock-dependent economy as a new paradigm of human civilisation although this remains an abstract idea (Matsui, 1998b). This concept is intended to guide sustainable development through the transition to a flow-dependent economy with supplementary support from a well-maintained stock in the anthroposphere. It would be difficult to return to the state of a flow-dependent economy as in historical agricultural societies, once humans have experienced a high level of economic development. However, the duration of a stock-dependent economy is limited by the rate of resource-depletion within the Earth system; Humans do not have sufficient capital to extend the anthroposphere to other planets or outer space.

\subsection{Ecological Economics}

The well-known operational principle of sustainability in the school of ecological economics follows that proposed by Daly (1990), which is summarised as:

1) Ecological services that are required in order to maintain life shall be conserved, and waste and pollution levels shall be within the natural assimilation capacity;

2) Consumption shall be within the capacity of renewable resource production;

3) Consumption of non-renewable resources shall be matched with investment in substitutable renewable resources.

This idea assumes that certain kinds and amounts of natural capital are essential not only for economic growth but also to maintain economic activities. Therefore, man-made capital is insufficient to substitute for natural capital in order to maintain human activities. This concept is called "strong" sustainability (Pezzey \&Toman, 2005).

One of the sustainability indicators within this conceptual theme is the ecological footprint. Ecological footprinting measures biological capacity, or the area of land that the ecosystem requires in order to produce the resources that humans consume, and to absorb the waste humans generate (Ecological Economics, 2000; Wackernagel \& Rees, 1996). An ecological footprint is an indicator of the extent to which these activities are achieved through the use of renewable resources, presented above. The use of non-energy biological capacity can be measured by excluding the footprint required to absorb carbon dioxide emitted for energy use.

\subsection{Neoclassical Economics}

Neoclassical economics analyses sustainability using the concepts of substitutability, decreasing return on 
investment, and technological change (Dasgupta \& Heal, 1974; Smulders, 2009; Solow, 1974; Stiglitz, 1974). According to this approach, substitution of natural resources by artificial (man-made) capital would mitigate the negative economic consequences associated with physical scarcity of resources. When there is a market, increasing price would signal increasing scarcity of the resources, giving incentives to develop substitutes. As long as man-made capital could replace the present resource and there were plenty of substitution options, the limits to growth would be avoided. Decreasing return on investment reduces capital accumulation along with decreasing available inputs of resources. Technological change could increase the productivity of capital and resources, which maintains growth, offsetting the decreasing return. Therefore, resource substitutability and technological innovation would determine the physical boundary of economic activities that require non-renewable resources as inputs.

An indicator of sustainability for non-renewable resources, within this market-based approach, is the extraction cost of primary energy resources. Physical depletion of non-renewable resources would not occur, as society as a whole tries to avoid depletion, because the depletion of resource stocks renders production, and hence consumption, impossible (Smulders, 2005). Neoclassical economics envisions that society would reduce its current use and, in return, slightly reserve the resources for future consumption, when approaching full depletion.

\subsection{Engineering}

The engineering sector within the oil industry has used Energy Profit Ratio (EPR), or equivalently Energy Return on Investment (EROI), to measure the physical sustainability of extracting non-renewable resources, in particular oil (Kaufmann \& Cleveland, 2001; Matsushima, 2010). The concept uses the physical unit, while the idea is quite similar to that of economics and business. EPR is defined as "the amount of energy supplied to the society" over "the amount of energy expended to obtain that energy" (See Figure 2). According to this idea, it is irrational and unsustainable to pursue primary energy resources that return an EPR of less than parity. Therefore, this idea claims that society would cease to use non-renewable resources such as oil before complete physical depletion of the resource within the Earth system.

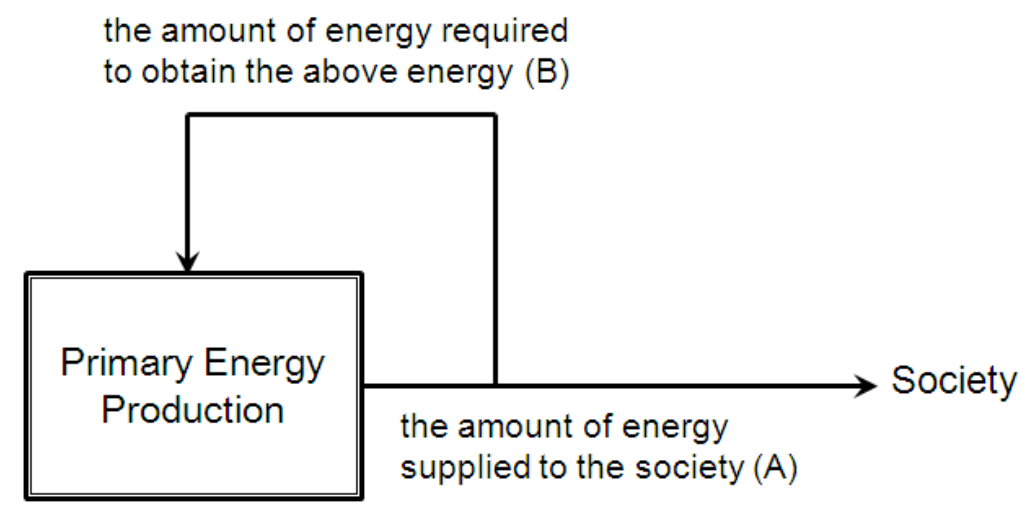

\section{Energy Profit Ratio $=\mathrm{A} / \mathrm{B}$}

Figure 2. Energy Profit Ratio is the energy supplied to society relative to the energy expended to obtain it

EPR is not a guideline of sustainability but rather an indicator to signal the state of availability and quality of non-renewable energy resources for humanity. It is considered that decreasing EPR could trigger high inflation and lasting stagnation (Matsushima, 2010). The use of EPR is also suggested to assess substitute energy technologies including solar photovoltaic power generation in order to improve scientific and rational decision-making. However, appropriate aggregation and measurement - including the issues of boundaries—of this type of physical indicator of sustainability remains contentious (Pezzey \& Toman, 2005).

\section{Discussion}

\subsection{Operational Principle}

In order to discuss the appropriate operational principle and indicators of physical and economic sustainability, it 
is necessary to distinguish material flow and energy flow. Material flow is basically reversible and could circulate within the Earth system and among various sub-systems within the Earth, although some light elements could transcend this boundary. Conversely, energy flow is an irreversible process and hence both solar thermal radiation as well as geothermal heat flow (the latter is less than one percent of the former) eventually dissipate from the Earth system. Irreversibility poses larger implications for sustainability.

Among the basic human needs of access to food, water and energy, the sustainability of food and water supplies forms part of material circulation, while energy is about the irreversible process of energy use. Moreover, food and water production, transportation and waste management require energy use; and energy production requires water utilisation. Here, energy demand comprises heat itself and a heat engine that utilises fuel.

First, the overall vision of a transition to natural flow and a man-made stock-dependent civilisation proposed to be based on knowledge from the earth sciences would be acceptable as a guiding principle of sustainability. However, it is necessary to pay attention to the difference between material flow and energy flow. It would be necessary for the energy used by humans to eventually transition entirely from a natural-stock-dependent society to a natural-flow-dependent society, although it is unclear when this might occur, or what the post-transition population level might be.

The first and second operational principles of sustainability proposed by ecological economics are basically identical to the concept of a flow-dependent economy used in earth sciences. This applies both for material and energy flows. Although a transition to natural flow and man-made stock-dependent society requires a certain period of dependency on natural energy stocks, the first operational principle also requires us to mitigate and manage the use of hydrocarbon stocks as well as nuclear energy stocks, since production of greenhouse gases and nuclear waste might violate the rule of "limit waste production and pollution levels to the natural assimilative capacity."

The third operational principal in ecological economics would require an amendment vis-à-vis the perspective of earth sciences, neoclassical economics and engineering. Earth sciences proposes the idea of a transition from the current natural-stock-dependent economy using finite natural stocks to a mixed natural flow and man-made stock-dependent economy. This is particularly significant for energy production and consumption, since natural material stock could be converted to man-made stock and could be well maintained, although a gradual attenuation is inevitable. The third principle implies maintaining the present level of energy production. However this is a strong statement and would lead to negative implications for social wellbeing, given the higher cost of energy production as well as lower EPR of substitute renewable energy options. It is also somewhat arbitrary to base the target for steady-state consumption on present levels. Therefore, the third principle might be revised as follows: Consumption of non-renewable resources shall be "associated" with investment in substitute renewable resources.

\subsection{Indicators}

Physical indicators that follow the above principles include: (a) Degree of dependence on natural hydrocarbon stock for heating (including fuel for motive power), transportation and electricity generation; and (b) EPR for natural hydrocarbon stock regarding natural energy stock. The dependence on - and state of - an ecosystem can be measured by (c) biocapacity using the non-energy ecological footprint. This would suggest that food production (and in some cases energy production) among the basic human needs is affected. A similar concept involves the human appropriation of net primary production (HANPP) (Vitousek et al., 1986), although it is also debatable whether this would produce a correct measurement (Pezzey \& Toman, 2005). The physical indicator for water, another basic human need, would be (d) water stress, which is the ratio of human water consumption over the total available water amount (Water - a Global Assessment and Prognosis [WaterGAP], 2012). Among these four suggested indicators, source data and calculations are relatively easily obtained for (a) and (d), whereas indicators (b) and (c) would present technical difficulties in data gathering, aggregation and boundary settings.

Economic indicators to measure the state of transition include the cost of excavation of natural hydrocarbon stock with regard to the scarcity of natural energy stock. Food and water prices might signal some portion of the state of (non-)sustainability of renewable material flows. However, this is questionable, since ecosystem services that are required to maintain food production and stable water circulation within the Earth system would not be accurately reflected in the market price. Therefore, there might not be appropriate economic indicators of the state of sustainability.

Although these physical and economic indicators are useful to monitor the overall direction of sustainability, natural and social sciences cannot provide accurate predictions for the future; rather they can only provide 
monitoring records, or their best estimate of the past and present states. It is necessary to differentiate what happened in the past from future uncertainty in order to consider a practical guide to actions for the sustainability transition. Possible use of the principle and indicators would be as follows:

1) Monitoring and learning based on assessment of the past using indicators

2) Early warning based on the trend inferred from the operational principle and indicators

\section{3) Adaptation of actions based on the indicators}

The principle and indicators themselves would not determine nor suggest the pace of transition from an economy dependent on natural energy stock to one dependent on natural flow and man-made stock, nor the level or magnitude of natural flow and man-made stock within the post-transition society. The speed of transition and the level of flow/stock following the transition can be determined through collective decision making apart from more-or-less spontaneous realisation through market mechanisms.

\subsection{Knowledge Production and Utilisation}

Operational principles for sustainability and relevant sustainability indicators are the knowledge produced by some individuals and/or groups, which is potentially shared and utilised in the society, from global to local scales. In order to assess the social process of knowledge production and utilisation towards the transition to a new civilisation, it is necessary to examine the reasons why some kinds of principles and indicators are widely produced, shared, or utilised whereas others - including the one proposed here - are not.

The perspectives of the earth sciences especially its sub-disciplines of Earth system science and planetary evolution have not been recognised within the environmental and sustainable development community, probably due to the large differential in the time horizons treated in these communities. Earth science deals with temporal scales reaching billion years, whereas sustainable development usually deals with issues within a timeframe of at most 100 years including issues such as climate change. Although some concerns regarding national energy security have similarities to the issue of transition to sustainable civilisation, their temporal and geographical scopes are different.

Another underlying factor would be the inclusive relationship between viewpoints from earth sciences and typical sustainability and environmental issues. Earth science views the problem of current civilisation as the question of stability of the anthroposphere as a sub-system of the Earth, which is wider than the frameworks used to describe various environmental issues. Logically, the stability of the Earth system is a precondition of a stable civilisation, while the society itself could deteriorate as a result of financial and/or societal instability that is not associated with the stability of the Earth system. These different temporal horizons and perspectives on the relationship between civilisation and the Earth would have led to less attention to incorporate earth science views into sustainability within the context of environmental management.

The environmental and sustainable development community does not commonly utilise the measures such as cost of excavation of non-renewable resources derived from conventional economics and EPR from geo-engineering. This is probably because these measures have a market-based rationale and business model, which do not capture collective decision-making process or activities of civil society that may go beyond the narrow economic motives to increase profit and avoid loss.

Moreover, the physical indicators proposed from ecological economics sometimes face difficulty in generating and objectively aggregating data, although some methods, such as ecological footprinting, are widely used. These practical difficulties would also have hindered the use of some indicators appropriate to measure the sustainability transition.

\section{Conclusion}

This paper reviewed the concepts used to measure the physical and economic sustainability of human civilisation proposed within the fields of earth sciences, ecological economics, neoclassical economics and engineering. It proposed a revised operational principle of sustainability, or transition towards new state of civilisation. The integrated principle can be summarised as: The overall vision of transition to natural flow and man-made stock-dependent civilisation using natural energy stock during transition; supplemented by the following amended operational principle:

1) Ecological services that are needed to maintain life shall be conserved and levels of waste and pollution shall be within the natural assimilative capacity;

2) Consumption shall be within the capacity to produce renewable resources; 
3) Consumption of non-renewable resources shall be associated with investment in substitute renewable resources.

This revised principle can be used to guide long-term transition efforts such as taxation, industrial transformation, science and technology research and development, development of alternative business models as well as investment and policy support. This also maps the various efforts that are currently termed environmentally friendly into those for transition towards a new civilisation or those to mitigate environmental problems within the current mechanism of civilisation. The physical and ecological foundation to discuss and formulate SDGs should also be examined and reviewed, based on this revised principle.

The paper also exemplified some indicators following the revised operational principle: (a) Degree of dependence on natural hydrocarbon stock regarding fuel consumption for heating, transportation and electricity generation; (b) EPR for natural hydrocarbon stock regarding natural energy stock; (c) non-energy ecological footprint for biocapacity; and (d) water stress. These could provide useful indicators of the past and present state and trend towards sustainability, which suggest the future limits of human activities.

The market might autonomously determine the rate of transition from fossil-fuel dependent economy to renewable energy dependent economy. However, the rate of transition to a sustainable civilisation could also be determined an appropriate elicitation mechanism and collective decision-making across society. These principle and indicators provide a good basis for monitoring and evaluation on transition. Adaptive management is required based on these principles and indicators.

The proposed principle and indicators would guide societal efforts to transition towards a sustainable civilisation. They suggest the disparity between the present state and the potential situation following the transition, although it is also a challenge to decide how to best utilise the hydrocarbon stock in order to cover the cost of resource substitution/transition to a steady-state economy. Daly's principle is actually used to guide the energy system transformation in Japan following a natural disaster on 11 March 2011 and consequent nuclear accident (Ueta, 2011). The proposed vision, principle, and indicators would also reaffirm and suggest the direction of this transformation. The Japanese government could consider explicitly incorporating the following indicators into its long-term energy, environmental, and economic policies: (a) Degree of dependence on natural hydrocarbon stock regarding fuel consumption for heating, transportation, and electricity generation; (b) EPR for natural hydrocarbon stock regarding natural energy stock.

Some may argue that the revised operational principle and associated indicators presented here are unlikely to be utilised in administration, business and civil societies. The indicators that are presently used are not necessarily focused on the transition to a new state of civilisation; the inertia of maintaining these indicators might hinder adoption of the proposed principles particularly within the international discourse of sustainability. However, at least some likeminded national and local governments, business, financial and civil organisations could start to incorporate these concepts and indicators within their monitoring and goal-setting objectives. The goal could also be sustainable development, sustainable lifestyles and so forth. Therefore, the proposed principles and indicators are not contradictory to such agendas that have been already set by the various advocates, and hence could be incorporated within existing frameworks.

Since this paper focuses on the physical and economic aspects of sustainability in particular for energy production for human activities, other important aspects of sustainability in general such as subjective wellbeing, employment, inclusiveness, purchasing power and poverty shall be investigated in a much broader context in another research.

\section{Acknowledgements}

The author thanks Mark Elder for his comments to develop the paper. The conclusions that are reached in this paper should be understood to be those of the author and not attributed to staff-members, officers, directors, trustees, funders, or to the organisation itself the author belongs to.

\section{References}

Daly, H. E. (1990). Toward some operational principles of sustainable development. Ecological Economics, 2 , 1-6. http://dx.doi.org/10.1016/0921-8009(90)90010-R

Dasgupta, P. S., \& Heal, G. M. (1974). The optimal depletion of exhaustible resources. Review of Economic Studies, Symposium on the Economics of Exhaustible Resources, 3-28.

Ecological Economics. (2000). Forum: The Ecological Footprint. 32 (3 March).

Hall, C. A. S., Powers, R., \& Schoenberg, W. (2008). Peak oil, EROI, investments and the economy in an 
uncertain future. In P. David (Ed.). Renewable energy systems: Environmental and energetic issues (pp. 109 - 132). London: Elsevier.

Hoff, H. (2011). Understanding the Nexus. Background paper for the Bonn 2011 Conference: The water, energy and food security nexus. Stockholm: Stockholm Environment Institute.

Kanie, N., Iguchi, M., Miyazawa, I., \& Yoshida, T. (2012). Chikyu shisutemu seiyaku ka no posuto MDGs sakutei he muketa doko (State towards post-MDGs development under the earth system constraint), Background paper presented at post-MDGs workshop, Yokohama, Japan, 1-2 June.

Kaufmann, R. K., \& Cleveland, C. J. (2001). Oil production in the lower 48 states: Economic, geological, and $\begin{array}{lllll}\text { institutional determinants. } & \text { Energy } & \text { Journal, } & \text { 22, }\end{array}$ http://dx.doi.org/10.5547/ISSN0195-6574-EJ-Vol22-No1-2

Matsui, T. (1998a). Ningen ken to ha nani ka (What is anthroposphere?) In M. Toriumi (Ed.). Shakai chikyu kagaku (Social-earth science) (pp. 1 - 12). Tokyo: Iwanami Shoten.

Matsui, T. (1998b). Ningen ken no antei sei (Stability of anthroposphere) In M. Toriumi (Ed.). Shakai chikyu kagaku (Social-earth science) (pp. 219 - 228). Tokyo: Iwanami Shoten.

Matsushima, J. (2010). Enerugi shushi hi teki shiten ga naze juyo nanoka: EPR no teigi to saikento (Why the perspective of energy profit ratio is significant? Re-examining definition and significance of EPR). An Electronic Journal of The MOTTAINAI Society, 3, 42-47. Retrieved from http://www.mottainaisociety.org/mso_journals/vol3/matsushima_p42_47.pdf

MOE. (2011). Annual report on the environment, the sound material-cycle society and the biodiversity in Japan 2011. Retrieved from http://www.env.go.jp/en/wpaper/2011/index.html

Pezzey, J. C. V., \& Toman, M. A. (2005). Sustainability and its economic interpretation. In R.D. Simpson, M.A. Toman, \& R.U. Ayres (Eds.). Scarcity and Growth Revisited: Natural Resources and the Environment in the New Millennium (pp. 121-141). Washington DC: Resources for the Future.

Rockstrom, J., Steffen, W., Noone, K., Persson, Å., Chapin, F. S., Lambin, E. F., Lenton, T. M., ...Foley, J. A. (2009). A safe operating space for humanity. Nature, 461, 472-475. http://dx.doi.org/10.1038/461472a

Smulders, S. (2005). Endogenous technological change, natural resources, and growth. In R. D. Simpson, M. A. Toman, \& R. U. Ayres (Eds.). Scarcity and Growth Revisited: Natural Resources and the Environment in the New Millennium (pp. 155 - 176). Washington DC: Resources for the Future.

Solow, R. M. (1974). Intergenerational equity and exhaustible resources. Review of Economic Studies, Symposium on the Economics of Exhaustible Resources, 29-46.

Stiglitz, J. E. (1974). Growth with exhaustible natural resources: Efficient and optimal growth paths. Review of Economic Studies, Symposium on the Economics of Exhaustible Resources, 123-137.

Stiglitz, J. E., Sen, A., \& Fitoussi, J-P. (2010). Mismeasuring Our Lives: Why GDP doesn't Add up. The report by the Commission on the Measurement of Economic Performance and Social Progress. New York, NY: The New Press.

Ueta, K. (2011). Enerugi sisutemu no sai sekkei (Re-designing energy system). In K. Ueta \& H. Kajiyama (Eds.). Kokumin no tame no Enerugi Genron (The New Energy Concept after 3.11) (pp. 303 - 318). Tokyo: Nihon Keizai Shimbun Shuppansha.

UNDESA. (2012). Current ideas on sustainable development goals and indicators, issues brief. Retrieved from http://www.uncsd2012.org/rio20/index.php?page=view\&type $=400 \& n r=218 \&$ menu $=45$

UNEP. (2009). Planning for Change: Mainstreaming Sustainable Consumption and Production and Resource Efficiency into Development. Paris: United Nations Environment Program.

UNEP. (2012). Global Environment Outlook 5: Environment for Development. Paris: United Nations Environment Program.

Vitousek, P. M., Ehrlich, P. R., Ehrlich, A. H., \& Matson, P. A. (1986). Human appropriation of the products of photosynthesis. Bio-Science, 36, 368-373. http://dx.doi.org/10.2307/1310258

Wackernagel, M., \& Rees, W. (1996). Our Ecological Footprint: Reducing Human Impact on the Earth. Gabriola Island, BC, Canada: New Society Publishers.

WaterGAP. (2012). Global modeling of water availability, water use, and water quality. Retrieved from http://www.usf.uni-kassel.de/cesr/index.php?option=com_project\&task=view_detail\&agid=47\&lang=en 